\title{
Royal Society may acquire an expanded role
}

\begin{abstract}
The ways in which Canada's Royal Society might have a broadened role in the country's scientific affairs is becoming a matter of some controversy. From Ottawa, David Spurgeon reviews the main issues, which focus chiefly on the question of relations with the government.
\end{abstract}

THE contract for $\$ 75,000$ over a 12 month period which was signed not long ago between the Canadian federal government and the Academy of Sciences of the Royal Society of Canada will enable the academy to undertake a study to identify specific missions in the natural and human sciences that may be of value to the government, and to recommend policies and procedures for carrying them out. Thus, apart from allowing the academy to engage an executive director half-time-he is Donald Hurst, former head of the Atomic Energy Control Board of Canada, the country's regulatory agency in nuclear affairsthe contract may give it a broadened role in Canada's scientific affairs, the implications of which do not delight all its members.

A number of initiatives designed to make the Royal Society more influential in scientific affairs has been taken in recent years. Five years ago, a committee set up by the Society's old Section Three (now the Academy of Sciences) to study how this could be done became a committee of the Society as a whole within months. Now there are three component academies in the Society, the other two being those of the social sciences and humanities (one for the Anglophone section, the other for the French).

One of the reasons some have felt the need of a stronger role for the Royal Society in science was expressed by the geologist $J$. Tuzo Wilson when he was president in 1973. In an article in Science Forum he said that the Society believed that Canada needed "an active and independent academy, not so much to advise government, but to promulgate informed opinions and to lead open discussions of important issues that will aid governments in making their decisions".

Dr Wilson stressed that, unlike the various bodies the government had established for similar purposes, the Royal Society was not a political body. $\mathrm{He}$ suggested that its independence, together with its access to leading scientists in many fields, could provide the alternative in scientific advice that the country needed. It was his view that the whole direction of Canadian science was in the hands of civil servants and members of councils who are appointed by ministers, and he claimed that the whole direction of science had been "politicised".

Not all Society members have agreed on the role the body should take, however. Although some, like Wilson, thought a detached role (in which the Society would make studies in specific areas) was best, others thought it should be closer to the government and play a more official advisory role.

Part of the Society's expanded role may be in international scientific affairs. In other countries, contacts with international scientific unions are usually made through non-governmental bodies, but in Canada the National Research Council has usually provided the point of contact. Some think this anomalous. For the social sciences, the humanities and engineering, Canada has non-governmental organisations that can act as adhering bodies to the international unions: the Social Science Research Council, the Humanities Research Council, and the Canadian Council of Professional Engineers. But there are no corresponding non-governmental bodies for international contact in the medical and natural sciences.

Some members of the Royal Society believe this is a role the Society should play, as academies do in other countries. But the problem of how this could be done remains because of the large number of professional organisations in different disciplines in Canada and the number of constituent bodies of the international scientific unions. One suggestion is that the Society should play the role of clearing house for the appropriate national professional organisations.

A certain amount of scepticism usually accompanies changes which the Royal Society of Canada makes, mainly because many scientists have become accustomed to thinking of the organisation as a self-congratulatory old boys' club. In spite of this, the 'club' counts among its members many of the country's most distinguished scientists (and lately even a few engineers), and it has been stirring itself in recent years to play a more important public role-for example by organising seminars on such topics as the energy problem. The outcome of this latest move will thus be watched with interest.

\section{BRITAIN \\ University pay grumbles remain}

Last year British university teachers were involved in 'industrial action' before finally resolving their dispute with the government over salary increases. The government has since introduced its pay policy. This month many academics will receive for the first time the cost of living element of their 1975 salaries settlement. David $W$ alker reports on the discontent that still prevails.

THE Association of University Teachers (AUT), the university authorities and the British goverment have agreed that the pay code maximum of $£ 6$ a week should be added to all academic salaries under $£ 8,500$ a year, and the whole package backdated to October. The final figures for the delayed settlement-the basic element was determined by an arbitration body as long ago as May last year-show that junior lecturers have probably benefited most and now start their teaching careers on nearly $£ 3,200$ a year. Some staff, who will no doubt bear in mind $\mathrm{Mr}$ Healey's recent warning about "confetti money", have increased their annual salaries by $£ 1,000$ in the space of 12 months. And one professor of politics told the world on television before Christmas that he was "aggressively satisfied" with his standard of living.

Under the settlement the starting point for all university academic staff, the foot of the lecturer grade, is $£ 3,174$ a year rising through 16 incremental points to $£ 6,446$. The scale for senior lecturers and readers will now run from $£ 6,234$ to $£ 7,742$, and the professorial minimum salary will be just below $£ 7,900$. Professors outside the clinical subjects will be on an average of over $£ 9,200$, although few of them got the $£ 6$ a week element or at least got only enough of it to take them to the $£ 8,500$ salaries ceiling. The settlement will run for the duration of the Labour government's incomes policy and Mr Laurie Sapper, the general secretary of the AUT, claims they have extracted from the government a firm promise to revise the scales of payment as soon as economic circumstances permit.

In spite of that, there is a lingering mood of dissatisfaction in those senior common rooms where salaries get discussed-and it is a sign of the times that money now gets talked about in public. Those university teachers who take an active part in their trade union (and a key test of their 'militancy' will come in March when they will vote on whether the AUT should affiliate to 
the Trades Union Congress, TUC) are still disgruntled. One of the major issues they still consider unresolved is the question of comparisons between their salaries and those paid to polytechnic lecturers and heads of departments.

Straight comparisons between rewards in the two sectors of British higher education are notoriously difficult to make on account of different opportunities for promotion, the numbers of staff, on relative salary points and the balance in teachers' time between teaching and research. Yet they are made, and the AUT officially considers that many university people are comparatively underpaid.

In addition the bi-annual conference of the AUT last December showed that the government's handling of negotiations on pay during the past year has left a legacy of bitterness. There is talk of "hatred" for the universities in the Department of Education and Science, discrimination in favour of the polytechnics, and-most disturbing-of a Civil Service plot to do down the universities.

The worst of these suspicions are likely to clear in the coming year, however. Mr Fred Mulley, the Secretary for Education, is a genial figure who attracts none of the opprobrium heaped on his predecessor, $\mathrm{Mr}$ Reg Prentice. Although the university teachers are likely to vote in favour of joining the TUC, it is unlikely that a moderate body like the AUT will do much to steel its arms for militant action on the issue of salaries.

But action is promised on two fronts that could have important longer term effects on the structure of the profession. The AUT is planning to press for a revision of the ratios of senior to junior staff, on the grounds that there is a serious promotions log-jam, with a great build-up of those on the upper points of the lecturer and senior lecturer scales with little or no prospect of advancement. On another front the AUT is drawing up new salary claims to be presented to the government on the basis of comparison with the Civil Service. This marks an unwelcome development in the eyes of those who fear that the drawing of such analogies will speed the process of bringing universities into full state control.
FORTY-EIGHT years ago I published the first of a series of papers on the exponential growth of colonies of duckweed and the circumstances under which exponential growth curves became sigmoid. I was following the fashion at that time. Raymond Pearl was doing elegant mathematical analyses of the growth rates of human populations, and Alfred Lotka's brilliant Elements of Physical Biology (surely one of the most seminal books on mathematical biology ever written) came into my hands when I was a third year student, just 50 years ago. It is a book which gave, as long ago as that, a masterly treatment of the conditions for equilibrium in biological systems.

So it is with a sensation of nostalgia that I have followed the publications sponsored by the Club of Rome and supervised by Dennis Meadows. It is touching to watch the rediscovery of exponentials, as though Pearl and Lotka had never lived, and ironical to note how much more credible those writers were, working with a slide rule and a little algebra, than Meadows and his colleagues are, armed with a computer. With these thoughts in mind I turned with hope rather than anticipation to the third volume of studies sponsored by the Club of Rome (Dynamics of Growth in a Finite World. Pp. 637; Wright Allen; Cambridge, Massachusetts, 1975). Have the authors, as I hoped, at last recognised the fundamental weakness of computer simulations in which the critical parameters - the adaptation of social values and norms to environmental change- have to be omitted because they cannot be quantified?

If this third volume does nothing else, it illustrates the phenomenon of exponential growth. The first volume weighs $170 \mathrm{~g}$ and cost $\$ 2.75$; the second weighs $530 \mathrm{~g}$ and cost $\$ 18$; the third weighs about $900 \mathrm{~g}$ and costs (in sterling) the equivalent of $\$ 37$. If one makes the assumptions which are the theme of The Limits to Growth, the next volume, due in a couple of years,

\section{Exponentials again}

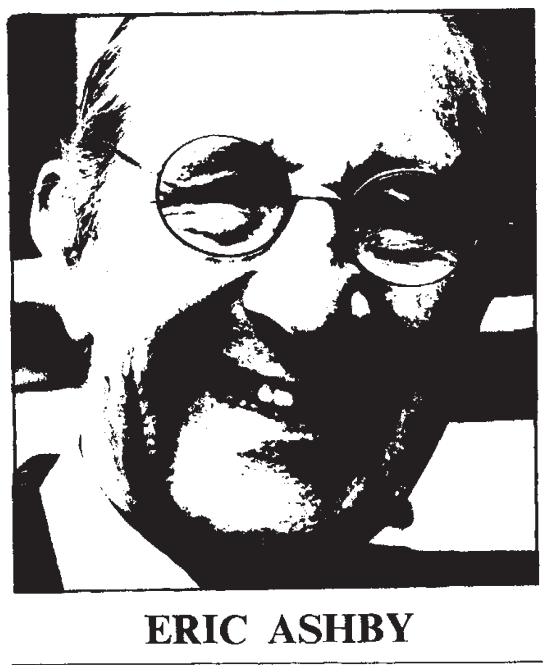

will weigh $1 \frac{1}{2} \mathrm{~kg}$ and cost about $\$ 60$, and the one after that $5 \mathrm{~kg}$, perhaps.

of course nobody in his senses makes such assumptions, but then neither does he make similar ones about the exponential increase of pollution in nations which have NEPA or the EEC Declaration on the Environment or the Control of Pollution Act; yet a section in chapter six of this book does make precisely this assumption, and the authors reach a conclusion which I think (without immodesty) I could have reached without a computer: " . . . as long as there is exponential growth in the generation of pollution, ameliorative measures ultimately do little to prevent the model from exhibiting unacceptable levels of pollution damage" (page 477).

We owe a debt to Meadows and his colleagues for dispelling the utopian mirage: that material standards of living will continue to go up and up, until Indian peasants enjoy the comforts and amenities now enjoyed by the middle classes in Europe. But they do a disservice to their own cause when they imply that their computer simulations can be used as a guide to policy making. A glance at the present state of the world is enough to demonstrate that this naive approach (even though it does include an element of social feedback through the price mechanism) diverts attention from the much higher priorities in policy making. Long before we are starved of resources or smothered in excess population or choked by pollution we are in for a series of grave geopolitical confrontations, to be resolved either by war or by subjection for nations which need resources to conditions imposed by nations which own resources.

The world's future in the short run depends on how these confrontations are handled. The techniques for handling them are not in the hard sciences (though they will buy time) nor in econometrics (which has a dubious record of predictiveness). They are in social anthropology (to understand the nations which may inherit power), in ethology (to understand our own social behaviour under stress), in political science (to help us to devise political systems to match the complexity of post-industrial society). These are the fields which need massive support for research and development. I think sometimes that Britain suffers from a semantic anomaly: that Wissenschaft in Germany and Nauk in the USSR cover a much wider spectrum of disciplines than our word Science. 